\section{Lesbian, Gay, Bisexual and Transgender (LGBT) Issues in Virtual Worlds}

\author{
Bridget Marie Blodgett \\ Pennsylvania State University
}

\author{
Heng Xu \\ Pennsylvania State University
}

Eileen M. Trauth

Pennsylvania State University

\begin{abstract}
In virtual worlds, users interact with each other by creating virtual identities through avatars. As the avatar creation process is constrained by the assumptions of designers who develop the avatar creation tools, some potential participants in virtual worlds are forced into narrow social roles that may not accurately represent them. Drawing on structuration theory and trust literature, we develop a research agenda that addresses how avatar-based technologies and user social identities may be mutually constructed and how identity misrepresentation may impact trust in virtual worlds. This paper demonstrates the importance of a discussion of Lesbian, Gay, Bisexual and Transgender (LGBT) issues in virtual worlds. These issues require additional research that should closely examine the ongoing changes both in the technology facilitating the virtual worlds, as well as the social landscape that governs issues of diversity in general, and gender issues in particular.
\end{abstract}

ACM Categories: H.5.2, K.4.2

Keywords: Diversity, Gender, Social Identities, Trust, Virtual Worlds

Gender remains binary in virtual worlds. One is either a male or a female; no in-between is possible. Although they still remain a minority, gay and lesbian players have challenged these limitations. Since these limitations often are hard-coded into the software, they represent the solidifying of social stereotypes into the structures of the virtual world. Several virtual worlds allow players to marry each other but only if the avatar couples consist of heterosexual male and female.

As the avatar creation process is constrained by the assumptions of designers who develop the avatar creation tools, some potential participants in these virtual worlds are forced into narrow social roles that may not accurately represent them. Although a fair amount of literature has discussed how people make decisions about representing themselves when deciding on a avatar, little has been written about how people that do not fall easily into the designed character categories decide how to represent themselves or how potential misrepresentations may impact trust in the virtual worlds. These issues have lead to the development of two research questions:

1) How are avatar-based technologies and user social identities mutually constructed in virtual worlds?

2) How does identity misrepresentation impact trust in virtual worlds? 
These research questions may be pursued by employing an empirical research design based on the structuration theory (Cohen, 1989; Giddens, 1984) and trust literature (Luhmann, 1979; Rotter, 1971). Structuration theory addresses the balancing of agency and structure (i.e., the duality of structure): social structures make social action possible, and at the same time social action creates those very structures. When considering social life in virtual worlds, we argue that the developers, game controllers and users collectively construct the structure which is comprised of the physics of the world, the social rules set in place by the hosting power in the Terms of Service, as well as the informal rules of the virtual community. Structuration theory will be particularly useful for examining whether virtual worlds appropriately encode the social assumptions in the physical world, and how the avatar-based technologies and user social identities are mutually constructed in virtual worlds.

Trust is an important enabling factor in relations where there is uncertainty, risk, and fear of opportunism. It is one's belief that the other party will behave in a dependable, ethical and socially appropriate manner (Rotter, 1971). Trust is a central aspect in many economic or social relationships because of a deep-seated human need to understand the social surroundings, that is, to identify what, when, why, and how others behave (Rotter, 1971). Accordingly, trust is crucial in virtual worlds because of uncertainties inherent in virtual communities that are normally alleviated by physical presence in faceto-face communication. Identity misrepresentations constrained by the design of avatar characters may threaten trust and undermine the strength of social bonds developed in virtual worlds. Although the importance of trust in online environments has been addressed in prior studies that deal with identifiable parties, the nature and role of trust in anonymous parties (e.g., avatar to avatar) in virtual worlds remains unclear.

To address the gap in the literature dealing with selfpresentation of excluded minorities, deception, and trust, research can use qualitative and quantitative methods, including interviews, text analysis, observations, and survey. First, interviews can be conducted to gather data about the experiences of Lesbian, Gay, Bisexual, and Transgender (LGBT) users in virtual worlds and how their sexuality influences their experiences. Interviews can be conducted with virtual community developers to better understand the reasoning behind their choices for the avatar creation and the formal social rules of the world. Second, text analysis can be applied to National statistics relating to sexuality, trust and gaming, and texts produced by LGBT users in forums and LGBT websites to develop a historical context for the research. Third, verbal walkthrough studies can be conducted to understand the reasons behind character development choices with LGBT individuals from the first interview phase. Finally, a survey among LGBT users can validate the relationships among self-presentation, deception, and trust.

There are several anticipated results of this research. First, a framework could be developed for the analysis of social exclusion in virtual worlds and how players enact agency to ease the social restriction they experience. The framework would take into account the multiple factors that come into play during the development of an informal social structure and analyze these factors so that countermeasures or actions could be produced to aide excluded individuals. The second outcome of the research would be a framework for understanding how people form trust relationships in virtual worlds when an avatar, due to structural limitations in character development, misrepresents a user. The final outcome would be an outline for possible critical or action research meant to change how assumptions become encoded into virtual worlds.

In conclusion, the outlook for virtual worlds depends on user recognition of virtual worlds as a social environment with the same complexities of trust and self-presentation that are a part of the world at large. Using the groundwork laid out in this proposal as a foundation, scholars can continue to pursue this line of research to further understand the diversity and development of users in the emerging virtual worlds.

\section{References}

Cohen, I.J. (1989). Structuration Theory: Anthony Giddens and the Constitution of Social Life, St Martin's Press: New York.

Giddens, A. (1984). The Constitution of Society, Berkeley: University of California Press.

Luhmann, N. (1979). Trust and Power, John Wiley \& Sons: Chichester, England.

Rotter, J.B. (1971). "Generalized Expectancies for Interpersonal Trust," American Psychologist, Vol. 26, pp. 443-450.

\section{About the Authors}

Bridget Marie Blodgett is a $\mathrm{PhD}$ student of Information Sciences and Technology at Pennsylvania State University. Her research interests include the development of virtual communities and the social issues that have arisen around these technologies as well as group collaboration in such spaces. 
Heng $\mathbf{X u}$ is an assistant professor of Information Sciences and Technology at Pennsylvania State University. She received her PhD degree in IS from National University of Singapore (2005). Her research interests include information privacy and trust management, human-computer interaction, and technology innovation adoption. Her doctoral dissertation was named as the runner up for 2006 ACM SIGMIS Doctoral Dissertation Award Competition.
Eileen M. Trauth is Professor of Information Sciences and Technology and Director of the Center for the Information Society at Pennsylvania State University. Her research concerns socio-cultural influences on IT and the IT profession with focus on diversity's role within the field. As a Fulbright Scholar, she investigated socio-cultural influences on the emergence of Ireland's information economy. 